\section{Rivastigmine for Dementia Associated with Parkinson's Disease}

\author{
Murat Emre, M.D., Dag Aarsland, M.D., Ph.D., Alberto Albanese, M.D., \\ E. Jane Byrne, F.R.C.Psych., M.B., Ch.B., Günther Deuschl, M.D., \\ Peter P. De Deyn, M.D., Ph.D., Franck Durif, M.D., Ph.D., Jaime Kulisevsky, M.D., \\ Ph.D., Teus van Laar, M.D., Ph.D., Andrew Lees, M.D., Werner Poewe, M.D., \\ Alain Robillard, M.D., F.R.C.P.C., Mario M. Rosa, M.D., Erik Wolters, M.D., Ph.D., \\ Peter Quarg, M.Sc., Sibel Tekin, M.D., and Roger Lane, M.D.
}

ABSTRACT

BACK GROUN D

Cholinergic deficits are prominent in patients who have dementia associated with Parkinson's disease. We investigated the effects of the dual cholinesterase inhibitor rivastigmine in such patients.

METHODS

Patients in whom mild-to-moderate dementia developed at least 2 years after they received a clinical diagnosis of Parkinson's disease were randomly assigned to receive placebo or 3 to $12 \mathrm{mg}$ of rivastigmine per day for 24 weeks. Primary efficacy variables were the scores for the cognitive subscale of the Alzheimer's Disease Assessment Scale (ADAS-cog) and Alzheimer's Disease Cooperative Study-Clinician's Global Impression of Change (ADCS-CGIC). Secondary clinical outcomes were the scores for the Alzheimer's Disease Cooperative Study-Activities of Daily Living, the 10-item Neuropsychiatric Inventory, the Mini-Mental State Examination, Cognitive Drug Research power of attention tests, the Verbal Fluency test, and the Ten Point Clock-Drawing test.

RESULTS

A total of 541 patients were enrolled, and 410 completed the study. The outcomes were better among patients treated with rivastigmine than among those who received placebo; however, the differences between these two groups were moderate and similar to those reported in trials of rivastigmine for Alzheimer's disease. Rivastigmine-treated patients had a mean improvement of 2.1 points in the score for the 70-point ADAS-cog, from a baseline score of 23.8, as compared with a 0.7-point worsening in the placebo group, from a baseline score of $24.3(\mathrm{P}<0.001)$. Clinically meaningful improvements in the scores for the ADCS-CGIC were observed in 19.8 percent of patients in the rivastigmine group and 14.5 percent of those in the placebo group, and clinically meaningful worsening was observed in 13.0 percent and 23.1 percent, respectively (mean score at 24 weeks, 3.8 and 4.3 , respectively; $\mathrm{P}=0.007$ ). Significantly better outcomes were seen with rivastigmine with respect to all secondary efficacy variables. The most frequent adverse events were nausea (affecting 29.0 percent of patients in the rivastigmine group and 11.2 percent of those in the placebo group, $\mathrm{P}<0.001$ ), vomiting (16.6 and 1.7 percent, $\mathrm{P}<0.001$ ), and tremor (10.2 and 3.9 percent, $\mathrm{P}=0.01$ ).

CONCLUSIONS

In this placebo-controlled study, rivastigmine was associated with moderate improvements in dementia associated with Parkinson's disease but also with higher rates of nausea, vomiting, and tremor.
From the Istanbul Faculty of Medicine, Istanbul University, Istanbul, Turkey (M.E.); Rogaland Central Hospital, Stavanger, Norway (D.A.); the School of Medicine, University of Bergen, Bergen, Norway (D.A.); Istituto Nazionale Neurologico Carlo Besta and Università Cattolica, Milan, Italy (A.A.); the University of Manchester, Manchester, United Kingdom (E.J.B.); ChristianAlbrechts-Universität Kiel, Kiel, Germany (G.D.); Middelheim Hospital, Zeikenhuis Netwerk Antwerpen, and the Born-Bunge Foundation, University of Antwerp, WilrijkAntwerp, Belgium (P.P.D.); Centre Hospitalier Universitaire Clermont-Ferrand, Clermont-Ferrand, France (F.D.); Sant Pau Hospital, Barcelona, Spain (J.K.); Groningen University Hospital, Groningen, the Netherlands (T.L.); the Reta Lila Weston Institute for Neurological Studies, University College London, London (A.L.); Innsbruck Medical University, Innsbruck, Austria (W.P.); Hôpital MaisonneuveRosemont, Montreal (A.R.); Hospital de Santa Maria, Lisbon, Portugal (M.M.R.); the Research Institute for Neurosciences, Vrije Universiteit Medical Center, Amsterdam (E.W.); Novartis Pharma, Basel, Switzerland (P.Q.); and Novartis Pharmaceuticals, East Hanover, N.J. (S.T., R.L.). Address reprint requests to Dr. Emre at Istanbul Tip Fakültesi, Nöroloji Anabilim Dalı, 34390 Capa, Istanbul, Turkey, or at muratemre@ superonline.com.

N Engl J Med 2004;351:2509-18.

Copyright (๑) 2004 Massachusetts Medical Society. 
$\mathrm{D}$

EMENTIA IS COMMON AMONG PAtients with Parkinson's disease, with an average prevalence of 40 percent in crosssectional studies ${ }^{1}$ and a cumulative prevalence approaching 80 percent. $^{2}$ The clinical phenotype is characterized by cognitive slowing, attentional deficits, and executive, visuospatial, and memory impairments ${ }^{3}$ and shares many clinical and pathological similarities with dementia with Lewy bodies. ${ }^{4}$ Dementia associated with Parkinson's disease is accompanied by a reduced quality of life for both patients ${ }^{5}$ and caregivers ${ }^{6}$ and by rapid functional and motor decline. ${ }^{7}$

The pathological correlates of dementia associated with Parkinson's disease are not fully established, but numerous Lewy bodies are found outside of the substantia nigra, and in most cases, amyloid plaques and neurofibrillary tangles are present. ${ }^{8-10}$ Neurochemically, cholinergic deficits are the most consistent findings associated with cognitive and neuropsychiatric symptoms. ${ }^{11-13}$ To date, no treatment has been demonstrated to be effective. In a double-blind, placebo-controlled study, McKeith et al. ${ }^{14}$ showed that rivastigmine, an inhibitor of acetylcholinesterase and butyrylcholinesterase, led to meaningful treatment benefits in patients with dementia with Lewy bodies. Preliminary studies suggested that cholinesterase inhibitors were beneficial in patients who had dementia associated with Parkinson's disease. ${ }^{15-17}$ Therefore, we conducted a placebo-controlled study to evaluate the efficacy and safety of 24 weeks of rivastigmine ( 3 to $12 \mathrm{mg}$ per day) in such patients.

METHODS

\section{PATIENTS}

Patients were men or women who were at least 50 years old and who had received a diagnosis of Parkinson's disease according to the clinical diagnostic criteria of the United Kingdom Parkinson's Disease Society Brain Bank (now known as the QueenSquare Brain Bank) ${ }^{18}$ and a diagnosis of dementia due to Parkinson's disease according to the fourth edition of the Diagnostic and Statistical Manual of Mental Disorders (code 294.1). ${ }^{19}$ Patients had mild-tomoderately severe dementia as defined by a MiniMental State Examination (MMSE) score of 10 to 24 , with the onset of symptoms occurring at least two years after the diagnosis of Parkinson's disease.

Patients were required to have contact with a responsible caregiver at least three days per week; participants (if mentally competent or, if incompetent, their legally authorized representatives) and caregivers gave written informed consent. Exclusion criteria included the presence of any primary neurodegenerative disorder other than Parkinson's disease or other causes of dementia; a history of a major depressive episode; the presence of an active, uncontrolled seizure disorder; the presence of any disability or unstable disease unrelated to Parkinson's disease; known hypersensitivity to drugs similar to rivastigmine; and the use of a cholinesterase inhibitor or anticholinergic drugs during the four weeks before randomization. No changes were permitted in the dose of current dopaminergic medications within four weeks before and throughout the study, nor was the commencement of treatment with new psychotropic medications (except atypical neuroleptic agents for acute psychosis) permitted during this period.

Patients were recruited from centers in Austria, Belgium, Canada, France, Germany, Italy, the Netherlands, Norway, Portugal, Spain, Turkey, and the United Kingdom. Before the study was begun, the protocol, informed-consent form, and other information provided to patients and caregivers were reviewed by the institutional review board at each center. All procedures were conducted in accordance with the ethical standards of the responsible committee on human experimentation and with the Helsinki Declaration as revised in 1983.

\section{STUDY DESIGN}

This was a 24-week randomized, multicenter, double-blind, placebo-controlled clinical trial. Patients were randomly assigned to treatment with 3 to $12 \mathrm{mg}$ of rivastigmine (Exelon, Novartis) per day or placebo in a ratio of 2:1. The $2: 1$ ratio permitted the collection of more safety data in the rivastigmine group. Treatment started with $1.5 \mathrm{mg}$ of rivastigmine or placebo twice daily. Doses were increased by $3 \mathrm{mg}$ per day at intervals of at least 4 weeks during a 16-week dose-escalation period. The highest well-tolerated dose for each patient was maintained for the rest of the study. Dose adjustments were permitted in the case of adverse events or other problems.

On entry into the double-blind phase, patients were sequentially assigned the lowest available identification number at each center. Automated random assignment of treatment was performed with the use of a validated system, managed by Novartis Drug Supply Management. Blocking was done ac- 
cording to the study center. All personnel directly involved in the conduct of the study remained unaware of the treatment groups until all data had been retrieved and finalized for analysis.

\section{OUTCOMES}

Efficacy assessments were made at baseline, week 16 , and week 24 . Primary efficacy variables were the scores for the cognitive subscale of the Alzheimer's Disease Assessment Scale (ADAS-cog) ${ }^{20}$ and the Alzheimer's Disease Cooperative Study-Clinician's Global Impression of Change (ADCS-CGIC) ${ }^{21}$ at week 24, which were rated independently of each other and of clinical and motor evaluations. The cognitive portion of the ADAS assesses orientation, memory, language, visuospatial, and praxis functions. Scores can range from 0 to 70 , with higher scores indicating more severe impairment. The ADCS-CGIC is a seven-point categorical scale that provides a single global rating of change from baseline. A score of 1 indicates marked improvement; a score of 2, moderate improvement; a score of 3, minimal improvement; a score of 4 , no change; a score of 5, minimal worsening; a score of 6 , moderate worsening; and a score of 7 , marked worsening. Minimal changes were predefined as clinically detectable changes that did not affect a patient's clinical status; moderate changes as definite, detectable changes that had a corresponding effect on clinical status; and marked changes as those that had a dramatic effect on clinical status. Raters for the ADCS-CGIC were given special instructions to discount, as far as possible, potential behavioral and functional changes due to motor symptoms of Parkinson's disease. Before the study was initiated, investigators received two days of training on outcome measures to ensure that test administration was consistent across centers.

Secondary clinical outcome variables were the 24-week scores for six instruments: the Alzheimer's Disease Cooperative Study-Activities of Daily Living scale (ADCS-ADL), for which scores can range from 0 to 78 points, with higher scores indicating better functioning ${ }^{22}$; the 10-item Neuropsychiatric Inventory (NPI-10), for which scores can range from 0 to 120 points, with higher scores indicating more frequent or more severe behavioral symptoms ${ }^{23}$; the MMSE, for which scores can range from 0 to 30 points, with higher scores indicating better mental status $^{24}$; the Cognitive Drug Research (CDR) Computerized Assessment System power of attention tests, which assess simple and complex reaction times and digit vigilance, measured in milliseconds, with higher scores indicating worse attention ${ }^{25}$; and for the assessment of executive functions, the DelisKaplan Executive Function System (D-KEFS) Verbal Fluency test, which requires patients to produce as many words per minute as they can, starting with a particular letter, with higher scores indicating better performance, ${ }^{26}$ and the Ten Point Clock-Drawing test, for which scores can range from 0 to 10 points, with higher scores indicating better performance. ${ }^{27}$

Safety evaluations included recording all adverse events, results of laboratory tests, electrocardiographic results (obtained at screening and week 24), vital signs, and body weight (all visits). Adverse events were coded with the use of a standard glossary. A central laboratory conducted all laboratory evaluations. Changes in symptoms of parkinsonism were assessed at baseline and at weeks 16 and 24 by means of the motor-examination section (part III) of the Unified Parkinson's Disease Rating Scale (UPDRS), for which scores can range from 0 to 108 points, with higher scores indicating more severe motor symptoms. ${ }^{28}$ Concomitant medications and dose changes were recorded.

\section{STATISTICAL ANALYSIS}

Six-month data from studies of the effect of rivastigmine in patients with Alzheimer's disease show that the standard deviation for the change from baseline in the ADAS-cog score ranges from 6 to 7 points. To ensure that the study had adequate statistical power in case there was greater variability in the score among patients with Parkinson's disease, we assumed a standard deviation of 7.5 points. With the use of a two-sided test with a significance level of 0.05 , the enrollment of 531 patients was required for the study to be able to detect differences of more than 2.25 points in the ADAS-cog scores, and 525 patients were required to detect differences of more than 0.40 point in the ADCS-CGIC scores. Therefore, to ensure that the study had adequate statistical power, we planned to enroll 540 patients: 360 were to be assigned to rivastigmine and 180 to placebo.

Patients who received at least one dose of study medication and had at least one safety evaluation after baseline were included in the safety analysis. The primary efficacy population was predefined as all randomized patients who received at least one dose of study medication and who were assessed for one of the primary efficacy variables at baseline and at least once after baseline, whether or not they were 
receiving study drug at that time. Patients who discontinued treatment prematurely were encouraged to attend assessments at predefined times; when available, the results of these assessments were used for efficacy analyses. We used the last-observationcarried-forward method to impute values if no follow-up information was available. Because executive-function tests were not performed at all sites, analyses involving these tests included only patients who actually took these tests.

Statistical analyses were performed with the use of SAS software, version 8. Changes from baseline in the ADAS-cog scores were assessed by means of analysis of covariance, with baseline values used as covariates and treatment groups and countries as factors (centers in a given country were pooled for analysis). The main analysis of the ADCS-CGIC scores was based on a Cochran-Mantel-Haenszel test with the use of modified ridit scores (van Elteren test), with country as the stratification variable.
Secondary efficacy variables were analyzed by means of analysis of covariance, with treatment, country, and the corresponding baseline measurement used as covariates, or a Cochran-Mantel-Haenszel test. Frequencies of adverse events were compared between groups by means of Fisher's exact test. All reported P values are two-sided. There were no interim analyses.

The study was funded by Novartis and designed jointly by Novartis and the EXPRESS (Exelon in Parkinson's Disease Dementia Study) Study Management Group. Data were collected by investigators and coinvestigators, entered into a central database, and analyzed by Novartis. Novartis and the principal investigator vouch for the data and data analysis. A writing committee prepared an initial draft of the manuscript, based on a draft report provided by Novartis, and all authors contributed to its finalization through an iterative review process. Novartis placed no limitations on publication.

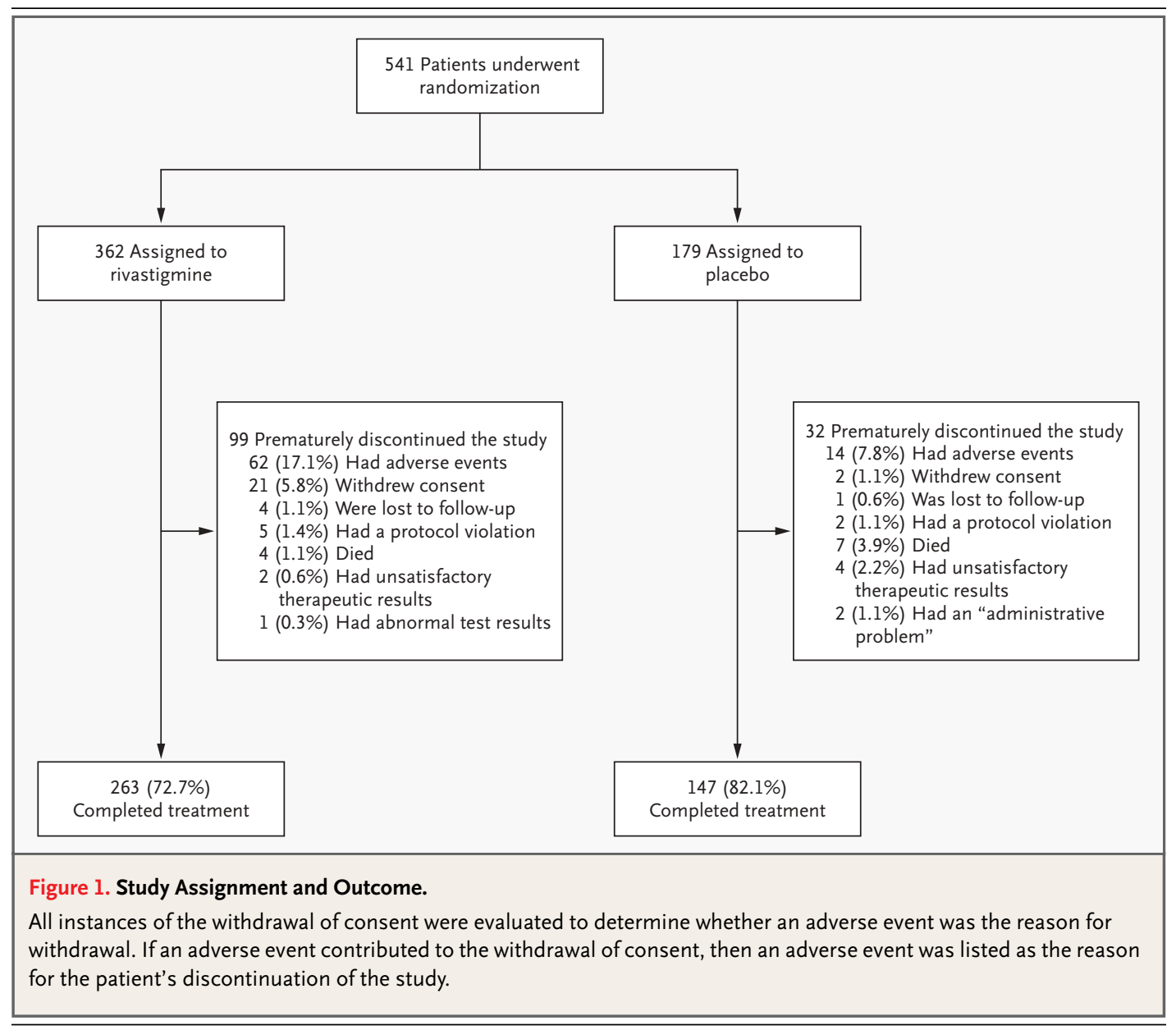




\section{RESULTS}

STUDY POPULATION

The first patient underwent randomization in October 2002, and recruitment was completed in July 2003. A total of 541 patients underwent randomization (Fig. 1): 362 patients were assigned to receive rivastigmine, and 179 to receive placebo. The mean age of the patients was 72.7 years, and 35.1 percent of the patients were women. Baseline demographic and background characteristics are summarized in Table 1; there were no significant differences in these characteristics between the two groups. All randomized patients received at least one dose of study drug.

Most patients (493 of 541, or 91.1 percent) had coexisting medical conditions at baseline. The most common were psychiatric disorders (in 218 patients, or 40.3 percent), such as depression, anxiety, insomnia, and psychosis, and vascular disorders (in 192, or 35.5 percent), such as hypertension and orthostatic hypotension. Among the patients who were receiving central nervous system drugs at baseline, the dose of antipsychotic drugs was decreased or treatment was discontinued during the study in 4 patients in the rivastigmine group (1.1 percent) and 3 patients in the placebo group (1.7 percent) and increased in 9 patients ( 2.5 percent) and 7 patients (3.9 percent), respectively; treatment with these drugs was initiated during the study in $26 \mathrm{pa}-$ tients ( 7.2 percent) and 20 patients (11.2 percent), respectively. The dose of dopaminergic drugs was decreased or treatment was discontinued during the study in 11 patients in the rivastigmine group (3.0 percent) and 9 patients in the placebo group (5.0 percent); increased in 21 (5.8 percent) and 7 (3.9 percent), respectively; and introduced in 34 (9.4 percent) and 16 (8.9 percent), respectively.

A total of 501 patients were included in the efficacy analysis; 27 patients were excluded from the rivastigmine group and 13 from the placebo group because no post-baseline efficacy data for either primary outcome measure were available for them. A total of 131 patients (24.2 percent) discontinued the study prematurely: 27.3 percent of those in the rivastigmine group and 17.9 percent of those in the placebo group (Fig. 1). Adverse events were the primary reason for discontinuation, resulting in the withdrawal of 17.1 percent of patients in the rivastigmine group and 7.8 percent of patients in the placebo group.

\begin{tabular}{|c|c|c|}
\hline Characteristic & $\begin{array}{l}\text { Rivastigmine } \\
\text { Group } \\
(\mathrm{N}=362)\end{array}$ & $\begin{array}{l}\text { Placebo Group } \\
(\mathrm{N}=179)\end{array}$ \\
\hline Age $-y r$ & $72.8 \pm 6.7$ & $72.4 \pm 6.4$ \\
\hline \multicolumn{3}{|l|}{ Sex-no. (\%) } \\
\hline Male & $234(64.6)$ & $117(65.4)$ \\
\hline Female & $128(35.4)$ & $62(34.6)$ \\
\hline \multicolumn{3}{|l|}{ Race or ethnic group — no. (\%) $\dagger$} \\
\hline White & $360(99.4)$ & $179(100)$ \\
\hline Other & $2(0.6)$ & 0 \\
\hline Years of education & $8.8 \pm 4.1$ & $9.2 \pm 3.9$ \\
\hline \multicolumn{3}{|l|}{ CNS medications - no. $(\%) \ddagger$} \\
\hline Antipsychotic agents & $100(27.6)$ & $47(26.3)$ \\
\hline Antidepressants & $102(28.2)$ & $42(23.5)$ \\
\hline Benzodiazepines, sedatives, hypnotics & $74(20.4)$ & 35 (19.6) \\
\hline Levodopa & $346(95.6)$ & $169(94.4)$ \\
\hline Dopamine agonists & $165(45.6)$ & $83(46.4)$ \\
\hline $\begin{array}{l}\text { Time since diagnosis of Parkinson's } \\
\text { disease }-y r\end{array}$ & $8.7 \pm 5.7$ & $9.5 \pm 5.9$ \\
\hline \multicolumn{3}{|l|}{$\begin{array}{l}\text { Modified Hoehn and Yahr stage } \\
\text { — no. (\%)』 }\end{array}$} \\
\hline 0 & $1(0.3)$ & 0 \\
\hline $1.0-2.5$ & $181(50.0)$ & $85(47.5)$ \\
\hline 3.0 & $114(31.5)$ & $63(35.2)$ \\
\hline 4.0 & $51(14.1)$ & $28(15.6)$ \\
\hline 5.0 & $15(4.1)$ & $2(1.1)$ \\
\hline UPDRS part III (motor function score) 9 & $34.0 \pm 14.6$ & $32.2 \pm 13.2$ \\
\hline Time since diagnosis of dementia $-\mathrm{yr}$ & $1.1 \pm 1.4$ & $1.3 \pm 1.9$ \\
\hline $\begin{array}{l}\text { Time between diagnosis of Parkinson's } \\
\text { disease and first symptoms of } \\
\text { dementia }-\mathrm{yr}\end{array}$ & $6.6 \pm 5.2$ & $7.3 \pm 5.2$ \\
\hline MMSE score\| & $19.4 \pm 3.8$ & $19.2 \pm 4.1$ \\
\hline \multicolumn{3}{|c|}{$\begin{array}{l}\text { * Plus-minus values are means } \pm \text { SD. } \\
\dagger \text { Race or ethnic group was determined by the investigators and recorded on the } \\
\text { case-report form with the use of the following categories; "Caucasian," } \\
\text { "Black," "Oriental," or "Other." } \\
+ \text { This category refers to central nervous system (CNS) medications taken with- } \\
\text { in four weeks before the start of the study. } \\
\text { I Part V of the United Parkinson's Disease Rating Scale (UPDRS) is a staging } \\
\text { instrument. Stage } 1 \text { indicates unilateral disease, and stages } 4 \text { and } 5 \text { advanced } \\
\text { bilateral disease. Data were missing for one patient in the placebo group. } \\
\text { 9 Scores for the UPDRS part III can range from } 0 \text { to } 108 \text {, with higher scores indi- } \\
\text { cating more severe motor symptoms. } \\
\text { | Scores for the Mini-Mental State Examination (MMSE) can range from } 0 \text { to } \\
30 \text {, with higher scores indicating better mental status. Values are based on the } \\
\text { efficacy population of } 335 \text { patients in the rivastigmine group and } 166 \text { patients } \\
\text { in the placebo group. }\end{array}$} \\
\hline
\end{tabular}




\begin{tabular}{|c|c|c|c|c|c|}
\hline \multirow[t]{3}{*}{ Variable } & \multirow[t]{3}{*}{ No. of Patients } & \multirow[t]{2}{*}{ Baseline Score } & \multirow[t]{3}{*}{ Change at Week 24} & \multicolumn{2}{|c|}{ Between-Group Difference at Week 24} \\
\hline & & & & Value & P Value \\
\hline & & mean $\pm S D$ & & & \\
\hline \multicolumn{6}{|c|}{ Primary efficacy variables } \\
\hline \multicolumn{6}{|l|}{ ADAS-cog score } \\
\hline Rivastigmine & 329 & $23.8 \pm 10.2$ & $-2.1 \pm 8.2$ & $2.90 \dagger$ & \\
\hline Placebo & 161 & $24.3 \pm 10.5$ & $0.7 \pm 7.5$ & & $<0.001$ \\
\hline \multicolumn{6}{|l|}{ ADCS-CGIC score } \\
\hline Rivastigmine & 329 & - & $3.8 \pm 1.4$ & 0.5 & \\
\hline Placebo & 165 & - & $4.3 \pm 1.5$ & & 0.007 \\
\hline \multicolumn{6}{|c|}{ Secondary efficacy variables } \\
\hline \multicolumn{6}{|l|}{ ADCS-ADL score } \\
\hline Rivastigmine & 333 & $41.6 \pm 18.6$ & $-1.1 \pm 12.6$ & 2.50 & 0.02 \\
\hline Placebo & 165 & $41.2 \pm 17.7$ & $-3.6 \pm 10.3$ & & \\
\hline \multicolumn{6}{|l|}{ NPI-10 score } \\
\hline Rivastigmine & 334 & $12.7 \pm 11.7$ & $-2.0 \pm 10.0$ & $2.15 \dagger$ & 0.02 \\
\hline Placebo & 166 & $13.2 \pm 13.0$ & $0.0 \pm 10.4$ & & \\
\hline \multicolumn{6}{|l|}{ MMSE score } \\
\hline Rivastigmine & 335 & $19.5 \pm 3.8$ & $0.8 \pm 3.8$ & 1.00 & 0.03 \\
\hline Placebo & 166 & $19.2 \pm 4.0$ & $-0.2 \pm 3.5$ & & \\
\hline \multicolumn{6}{|c|}{ CDR power of attention tests (msec) } \\
\hline Rivastigmine & 328 & $2197.0 \pm 1170.2$ & $-31.0 \pm 989.8$ & $294.84 \dagger$ & 0.009 \\
\hline Placebo & 158 & $2490.5 \pm 2314.8$ & $142.7 \pm 1780.2$ & & \\
\hline \multicolumn{6}{|c|}{$\begin{array}{l}\text { D-KEFS Verbal Fluency Test (total no. } \\
\text { of correct responses) }\end{array}$} \\
\hline Rivastigmine & 258 & $13.9 \pm 9.5$ & $1.7 \pm 6.8$ & 2.80 & $<0.001 \ddagger$ \\
\hline Placebo & 144 & $14.5 \pm 9.4$ & $-1.1 \pm 6.4$ & & \\
\hline \multicolumn{6}{|c|}{ Ten Point Clock-Drawing score } \\
\hline Rivastigmine & 49 & $3.4 \pm 3.7$ & $0.5 \pm 2.5$ & 1.10 & $0.02 \div$ \\
\hline Placebo & 30 & $2.9 \pm 3.8$ & $-0.6 \pm 2.4$ & & \\
\hline
\end{tabular}

* Scores for the cognitive subscale of the Alzheimer's Disease Assessment Scale (ADAS-cog) can range from 0 to 70 , with higher scores indicating more severe impairment; decreases in scores indicate improvement. Scores for the Alzheimer's Disease Cooperative Study-Clinician's Global Impression of Change (ADCS-CGIC) can range from 1 to 7 , with a score of 1 indicating marked improvement; a score of 2, moderate improvement; a score of 3 , minimal improvement; a score of 4, no change; a score of 5, minimal worsening; a score of 6 , moderate worsening; and a score of 7, marked worsening. There are no baseline scores for the ADCS-CGIC because this tool assesses change. Scores for the Alzheimer's Disease Cooperative Study-Activities of Daily Living (ADCS-ADL) can range from 0 to 78, with higher scores indicating better functioning. Scores for the 10-item Neuropsychiatric Inventory (NPI-10) can range from 0 to 120, with higher scores indicating more frequent or more severe behavioral symptoms. Scores for the Mini-Mental State Examination (MMSE) can range from 0 to 30, with higher scores indicating better mental function. Higher scores for the Cognitive Drug Research (CDR) computerized assessment system power of attention tests indicate worse performance. Higher scores for the Delis-Kaplan Executive Function System (D-KEFS) Verbal Fluency test and the Ten Point Clock-Drawing test indicate better performance.

$\dagger$ The value is the modeled treatment difference (difference of least-square means).

$\neq$ Because executive-function tests were not performed at all sites, analyses involving these tests included only patients who actually took these tests.

\section{EFFICACY}

The mean dose of rivastigmine was $8.6 \mathrm{mg}$ per day at the end of the dose-escalation phase and remained stable throughout the maintenance phase. At the end of the study, 201 patients (55.5 percent) were receiving 9 to $12 \mathrm{mg}$ of rivastigmine per day,
76 (21.0 percent) were receiving at least $6 \mathrm{mg}$ but less than $9 \mathrm{mg}$ per day, 83 (22.9 percent) were receiving at least $3 \mathrm{mg}$ but less than $6 \mathrm{mg}$ per day, and 2 ( 0.6 percent) were receiving less than $3 \mathrm{mg}$ per day. As compared with patients in the placebo group, patients who were receiving rivastigmine had sig- 
nificant improvements in ADAS-cog scores at week 24 (mean improvement of 2.1 points, as compared with a worsening of 0.7 point in the placebo group; $\mathrm{P}<0.001$ ), representing an 8.8 percent improvement in the rivastigmine group and a 2.9 percent deterioration in the placebo group, yielding an absolute difference of 11.7 percent (Table 2 and Fig. 2A). The mean scores for the ADCS-CGIC at week 24 were 3.8 in the rivastigmine group and 4.3 in the placebo group; an analysis comparing outcomes in the seven possible response categories (marked, moderate, or minimal improvement; no change; or marked, moderate, or minimal worsening) revealed that significantly more patients had a favorable outcome in the rivastigmine group than in the placebo group ( $\mathrm{P}=0.007)$ (Table 2 and Fig. $2 \mathrm{~B})$.

An analysis of those with a predefined response (any improvement) confirmed this result ( 40.8 percent of patients in the rivastigmine group had a favorable outcome, as compared with 29.7 percent of those in the placebo group; $\mathrm{P}=0.02$ ). Clinically meaningful (moderate or marked) improvement was observed in 19.8 percent of patients in the rivastigmine group and 14.5 percent of those in the placebo group. More patients in the placebo group than in the rivastigmine group had worsening symptoms (42.5 percent vs. 33.7 percent); marked or moderate worsening was seen in 13.0 percent of patients in the rivastigmine group and 23.1 percent of those in the placebo group.

Results of the analysis of secondary efficacy variables are shown in Table 2. Rivastigmine provided significant benefits over placebo, as reflected by the changes in the scores for the ADCS-ADL ( $\mathrm{P}=0.02)$, NPI-10 ( $\mathrm{P}=0.02)$, MMSE ( $\mathrm{P}=0.03)$, CDR power of attention tests $(\mathrm{P}=0.009)$, $\mathrm{D}-\mathrm{KEFS}$ Verbal Fluency test $(\mathrm{P}<0.001)$, and the Ten Point Clock-Drawing test $(\mathrm{P}=0.02)$. In addition, significantly more patients in the rivastigmine group than in the placebo group had an improvement of at least 30 percent on the NPI-10 scores (45.4 percent vs. 34.6 percent, $\mathrm{P}=0.03$ ).

To investigate possible bias owing to the exclusion of 40 patients from the efficacy analyses (patients who underwent randomization but for whom no data were available on primary efficacy variables after baseline), we performed a prospectively defined sensitivity analysis, including these patients and assuming no change from baseline in their primary outcome variables. We performed two further analyses, one including patients who had post-baseline efficacy assessments but did not complete the
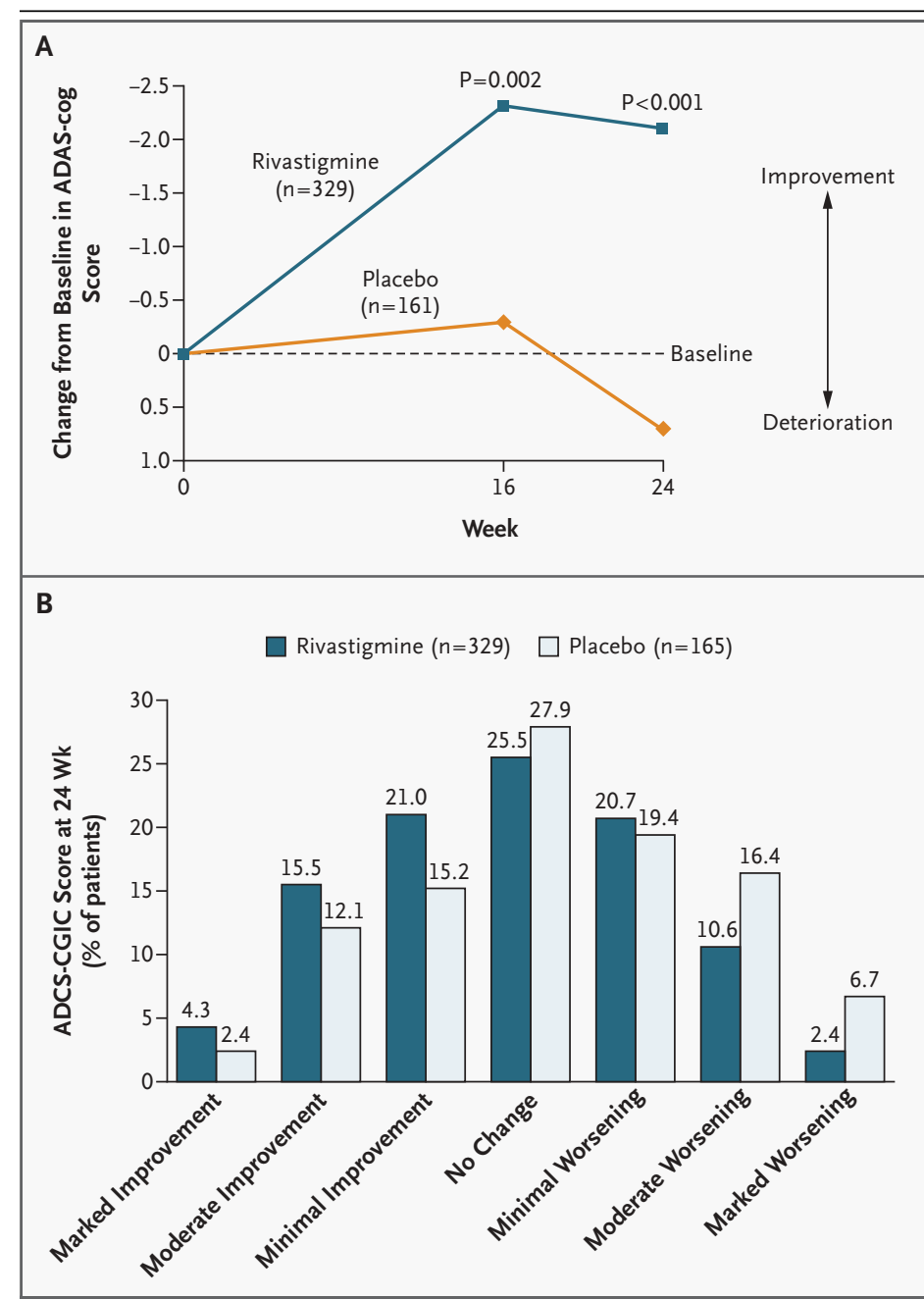

Figure 2. Results of the Primary Efficacy Analysis in the Efficacy Population. Panel $A$ shows the changes from baseline in the score for the cognitive subscale of the Alzheimer's Disease Assessment Scale (ADAS-cog). Scores can range from 0 to 70 , with higher scores indicating more severe impairment and decreases in scores indicating improvement. Panel B shows the scores for the Alzheimer's Disease Cooperative Study-Clinician's Global Impression of Change (ADCS-CGIC) at 24 weeks. Minimal changes were predefined as those that were clinically detectable but that did not affect a patient's clinical status; moderate changes were defined as definite, detectable changes that had a corresponding effect on clinical status; and marked changes were defined as those that had a dramatic effect on clinical status. $P=0.007$ for the overall difference between groups at 24 weeks. A few patients in the efficacy analysis had missing data on either of the two primary end points at week 24

study (last-observed efficacy data were carried forward in the case of missing values) and an analysis that included only patients with data, without imputation of missing values. Results from these three analyses were consistent with findings in the primary population (data not shown). Additional 
analyses of the effects of country and center did not reveal patterns affecting the interpretation of the results.

\section{TOLERABILITY AND SAFETY}

The predominant adverse events were cholinergic in nature, the most frequent being nausea (affecting 29.0 percent of patients in the rivastigmine group and 11.2 percent of those in the placebo group, $\mathrm{P}<0.001$ ) and vomiting (affecting 16.6 percent and 1.7 percent, respectively; $\mathrm{P}<0.001$ ) (Table 3). Most adverse events were mild or moderate. The occurrence of adverse events rated as serious was similar in both groups (13.0 percent in the rivastigmine group and 14.5 percent in the placebo group, $\mathrm{P}=$ 0.69 ). There were 11 deaths ( 4 in the rivastigmine group and 7 in the placebo group). There was a mean $( \pm S D)$ weight loss of $1.18 \pm 3.66 \mathrm{~kg}$ in the rivastigmine group and $1.53 \pm 4.38 \mathrm{~kg}$ in the placebo group at week 24.

Parkinsonian symptoms were reported as adverse events more frequently in the rivastigmine group than in the placebo group (27.3 percent vs. 15.6 percent, $\mathrm{P}=0.002)$. These events were most commonly manifested as tremor (affecting 10.2 percent of patients in the rivastigmine group, as compared with 3.9 percent of those in the place-

\begin{tabular}{|lccc|}
\hline \hline \multicolumn{4}{|c|}{ Table 3. Most Frequently Reported Adverse Events.* } \\
\hline Adverse Event & $\begin{array}{c}\text { Rivastigmine Group } \\
\text { (N=362) }\end{array}$ & $\begin{array}{c}\text { Placebo Group } \\
\text { (N=179) }\end{array}$ & P Value \\
Any & \multicolumn{2}{c}{ no) } & \\
Nausea & $303(83.7)$ & $127(70.9)$ & $<0.001$ \\
Vomiting & $105(29.0)$ & $20(11.2)$ & $<0.001$ \\
Tremor & $60(16.6)$ & $3(1.7)$ & $<0.001$ \\
Diarrhea & $37(10.2)$ & $7(3.9)$ & 0.01 \\
Anorexia & $26(7.2)$ & $8(4.5)$ & 0.26 \\
Falls & $22(6.1)$ & $5(2.8)$ & 0.14 \\
Dizziness & $21(5.8)$ & $11(6.1)$ & 0.85 \\
Hypotension & $21(5.8)$ & $2(1.1)$ & 0.01 \\
Constipation & $19(5.2)$ & $14(7.8)$ & 0.25 \\
Hallucinations & $17(4.7)$ & $12(6.7)$ & 0.32 \\
Confusion & $17(4.7)$ & $17(9.5)$ & 0.04 \\
Orthostatic hypotension & $13(3.6)$ & $10(5.6)$ & 0.36 \\
& $6(1.7)$ & $9(5.0)$ & 0.05 \\
\hline
\end{tabular}

* Adverse events occurring in at least 5 percent of the patients in either group are reported. bo group; $\mathrm{P}=0.01$ ), although tremor was severe enough to cause withdrawal from the study of only 1.7 percent of patients in the rivastigmine group and none of the patients in the placebo group $(\mathrm{P}=0.19)$. No other parkinsonian symptom (bradykinesia, dystonia, or muscle rigidity) accounted for more than 0.6 percent of withdrawals in either group. The difference with regard to the incidence of parkinsonian symptoms as adverse events was not reflected in significant differences in UPDRS motor scores between the two groups $(\mathrm{P}=0.83)$, including tremor-related items $(\mathrm{P}=0.84)$.

Other adverse events that contributed to premature withdrawal from the study included nausea (in 3.6 percent of patients in the rivastigmine group and 0.6 percent of those in the placebo group, $\mathrm{P}=0.04$ ) and vomiting (in 1.9 percent and 0.6 percent, respectively; $\mathrm{P}=0.28$ ). There were no significant differences between the groups with respect to clinically relevant changes in the results of laboratory tests, electrocardiograms, and vital signs.

\section{I SCUSSION}

As compared with placebo, rivastigmine produced moderate but significant improvements in global ratings of dementia, cognition (including measures of executive functions and attention), and behavioral symptoms among patients with dementia associated with Parkinson's disease. The magnitude of the effects (i.e., the difference between rivastigmine and placebo) in terms of the scores for the ADAScog and ADCS-CGIC were similar to those observed among patients with Alzheimer's disease who were treated with cholinesterase inhibitors. ${ }^{29,30}$ Scores for the ADAS-cog are a composite of various cognitive functions, and it is difficult to assign a single clinical meaning to a mean change in the score, since this can represent changes of different magnitude in individual domains, varying from patient to patient. A change in the ADAS-cog score of three to four points is thought to represent six months of symptom progression in patients with Alzheimer's disease, ${ }^{31}$ and this figure is frequently used as a reference in reporting the results of clinical trials involving patients with Alzheimer's disease.

Similar figures indicating the rate of progression as measured by the ADAS-cog score, however, are lacking for dementia associated with Parkinson's disease. In our study, patients receiving rivastigmine had a mean improvement of 2.1 points 
from a baseline score of 23.8 on the 70-point ADAS-cog scale, and those receiving placebo had a mean decline of 0.7 point (from a baseline score of 24.3) over a six-month period. Results obtained in a clinical trial, however, may not reflect the natural rate of deterioration in untreated patients. Whether these improvements are maintained over the long term in this chronic disorder is not known.

More patients in the rivastigmine group than in the placebo group had an improvement in the ADCS-CGIC score, whereas more patients in the placebo group worsened. On this scale minimal changes were predefined as clinically detectable changes that did not affect a patient's clinical status; moderate changes as definite, detectable changes that had a corresponding effect on clinical status; and marked changes as those that had a dramatic effect on clinical status. A higher percentage of patients in the rivastigmine group than in the placebo group had a moderate or marked improvement (19.8 percent vs.14.5 percent), whereas the opposite was true for moderate or marked worsening (13.0 percent vs. 23.1 percent). The absolute differences in the rates of improvement were small, and the majority of patients who were treated with rivastigmine (80.2 percent) had no clinically meaningful improvement, as reflected by ADCS-CGIC scores.

The profile of adverse events was compatible with an underlying mechanism of cholinergic stimulation. The most common were nausea and vomiting, consistent with published data on patients with Alzheimer's disease. Worsening of parkinsonian symptoms, mainly tremor, was more frequent among rivastigmine-treated patients but rarely resulted in withdrawal from the study. These reports were not reflected in changes in the overall scores or scores for individual items on the UPDRS motorfunction assessments at week 16 and at study termination, as compared with baseline scores or scores in the placebo group. These findings indi- cate that at least subjective worsening of parkinsonian symptoms, notably tremor, may occur in a subgroup of patients and must be specifically looked for during treatment. Taking into account the expected effect sizes and potential issues of tolerability, physicians should evaluate each patient individually before deciding to initiate treatment with rivastigmine.

In conclusion, rivastigmine resulted in a moderate but significant improvement in all symptoms of dementia associated with Parkinson's disease. The most frequent adverse events were nausea, vomiting, and tremor. In patients with Parkinson's disease, dementia is a major prognostic factor for progressive disability and nursing home placement, and thus our findings may have implications for clinical practice.

Dr. Emre reports having served as a paid consultant for, having received grant support from, and having received lecture fees from Novartis, Pfizer, Eisai, and Lundbeck. Dr. Aarsland reports having served as a paid consultant and speaker for Pfizer, AstraZeneca, Eli Lilly, Eisai, Lundbeck, and Janssen and having received grant support from Novartis, Pfizer, and Janssen. Dr. Albanese reports having served as a paid consultant and lecturer for Allergan, Medtronic, Novartis, and Teva. Dr. Byrne reports having served as a paid consultant and lecturer for Novartis and Janssen. Dr. Deuschl reports having served as a paid consultant for Novartis and a paid speaker for Orion, Medtronic, and Pfizer. Dr. De Deyn reports having served as a paid consultant for Johnson \& Johnson, Bristol-Myers Squibb, Novartis, and AstraZeneca; being a member of speakers' bureaus for Johnson \& Johnson, Bristol-Myers Squibb, and Lundbeck; and having received clinical or preclinical study grants, or both, from Johnson \& Johnson and Lundbeck. Dr. Durif reports having served as a paid consultant and speaker for Novartis. Dr. Kulisevsky reports having served as a paid consultant and speaker for Pfizer. Dr. van Laar reports having received lecture fees from Novartis. Dr. Lees reports having served as a paid consultant and speaker for Novartis. Dr. Poewe reports having acted as a consultant for and received lecture fees from Novartis, Pfizer, and Lundbeck. Dr. Robillard reports having served on advisory boards for Novartis, Janssen, Pfizer, and Lundbeck and having received grant support and honoraria for lectures from these companies, as well as from Sanofi, Neurochem, and Aventis. Dr. Rosa reports being a member of the Portuguese Drug Agency (INFARMED) and has not received any grants or other fees from any pharmaceutical company during the past five years. Dr. Wolters reports receiving fees for consulting and grant support from Teva and Novartis. Mr. Quarg, Dr. Tekin, and Dr. Lane are employees of Novartis and report owning share options in this company.

\section{APPENDIX}

The following were principal investigators in this study: Austria - W. Poewe; Belgium - P.P. DeDeyn, R. Dom, A. Jeanjean, E. Salmon; Canada - S. Chouinard, G. Marotta, T. de Mendis, M. Panisset, E. Pourcher, A. Robillard, T. Rosenberg; France - J.-P. Azulay, J. Boulliat, A. Destee, F. Durif, L. Lacomblez, R. Marié, P. Pollak, F. Tison, J. Touchon; Germany — D. Backhaus, R. Bodenschatz, G. Deuschl, G. Ebersbach, J. Faiss, T. Gasser, F. Klostermann, W. Mattern, W. Oertel, B. Rathay, H. Sommer, K. Tinschert; Italy - G. Abbruzzese, A. Albanese, P. Barone, U. Bonuccelli, M. Canesi, L. Grimaldi, G. Meco, G. Nordera, M. Onofrj, P. Stanzione, C.A. Tassinari; the Netherlands - T. van Laar, E. Wolters; Norway - D. Aarsland; Portugal - M. Rosa; Spain — G. Amer, E. Balaguer, M. Calopa, J. Kulisevsky, J. Lopez, D. Mateo, J. Peña, E. Tolosa; Turkey - B. Elibol, M. Emre (lead investigator), S. Özekmekci; United Kingdom - A. Bayer, D. Burn, J. Byrne, D. Gunawardena, A. Lees, M.-H. Marion, C. McWilliam, M. Steiger, S. Vethanayagam. 


\section{REFERENCES}

1. Cummings JL. Intellectual impairment in Parkinson's disease: clinical, pathologic and biochemical correlates. J Geriatr Psychiatry Neurol 1988;1:24-36.

2. Aarsland D, Andersen K, Larsen JP, Lolk A, Kragh-Sorensen P. Prevalence and characteristics of dementia in Parkinson disease: an 8-year prospective study. Arch Neurol 2003;60:387-92.

3. Emre M. Dementia associated with Parkinson's disease. Lancet Neurol 2003;2: 229-37.

4. McKeith I, Mintzer J, Aarsland D, et al. Dementia with Lewy bodies. Lancet Neuro 2004;3:19-28.

5. Schrag A, Jahanshahi M, Quinn N. What contributes to quality of life in patients with Parkinson's disease? J Neurol Neurosurg Psychiatry 2000;69:308-12.

6. Aarsland D, Larsen JP, Karlsen K, Lim NG, Tandberg E. Mental symptoms in Par kinson's disease are important contributors to caregiver distress. Int J Geriatr Psychiatry 1999;14:866-74.

7. Huber SJ, Paulson GW, Shuttleworth EC. Relationship of motor symptoms, intel lectual impairment, and depression in Parkinson's disease. J Neurol Neurosurg Psychiatry 1988;51:855-8.

8. Leech RW, Brumback RA, Poduslo SE, Schiffer R, Adesina A. Dementia: the University of Oklahoma autopsy experience. J Okla State Med Assoc 2001;94:507-11.

9. Apaydin H, Ahlskog JE, Parisi JE, Boeve BF, Dickson DW. Parkinson disease neuropathology: later-developing dementia and loss of the levodopa response. Arch Neurol 2002;59:102-12.

10. Braak H, Del Tredici K, Rub U, de Vos RA, Jansen Steur EN, Braak E. Staging of brain pathology related to sporadic Parkinson's disease. Neurobiol Aging 2003;24: 197-211.

11. Perry EK, Curtis M, Dick DJ, et al. Cholinergic correlates of cognitive impairmen in Parkinson's disease: comparison with Alzheimer's disease. J Neurol Neurosurg Psychiatry 1985;48:413-21. 12. Tiraboschi P, Hansen LA, Alford M, et al. Cholinergic dysfunction in diseases with Lewy bodies. Neurology 2000;54:407-11.

13. Bohnen NI, Kaufer DI, Ivanco LS, et al. Cortical cholinergic function is more severely affected in parkinsonian dementia than in Alzheimer disease: an in vivo positron emission tomographic study. Arch Neurol 2003 60:1745-8.

14. McKeith I, Del Ser T, Spano P-F, et al. Efficacy of rivastigmine in dementia with Lewy bodies: a randomised, double blind, placebo controlled international study. Lancet 2000 356:2031-6.

15. Reading PJ, Luce AK, McKeith IG. Rivastigmine in the treatment of parkinsonian psychosis and cognitive impairment: preliminary findings from an open trial. Mo Disord 2001;16:1171-4.

16. Aarsland D, Laake K, Larsen JP, Janvin C. Donepezil for cognitive impairment in Par kinson's disease: a randomised controlled study. J Neurol Neurosurg Psychiatry 2002; 72:708-12. [Erratum, J Neurol Neurosurg Psychiatry 2002;73:354.]

17. Giladi N, Shabtai H, Gurevich T, Benbunan B, Anca M, Korczyn AD. Rivastig mine (Exelon) for dementia in patients with Parkinson's disease. Acta Neurol Scand 2003;108:368-73.

18. Gibb WR, Lees AJ. The relevance of the Lewy body to the pathogenesis of idiopathic Parkinson's disease. J Neurol Neurosurg Psychiatry 1988;51:745-52.

19. Diagnostic and statistical manual of mental disorders, 4th ed.: DMS-IV. Washington, D.C.: American Psychiatric Association, 1994.

20. Rosen WG, Mohs RC, Davis KL. A new rating scale for Alzheimer's disease. Am Psychiatry 1984;141:1356-64.

21. Schneider LS, Olin JT, Doody RS, et al. Validity and reliability of the Alzheimer's Disease Cooperative Study-Clinical Global Impression of Change: the Alzheimer's Disease Cooperative Study. Alzheimer Dis Assoc Disord 1997;11:Suppl 2:S22-S32.

22. Galasko D, Bennett D, Sano M, et al. An inventory to assess activities of daily living for clinical trials in Alzheimer's disease: the
Alzheimer's Disease Cooperative Study. Alzheimer Dis Assoc Disord 1997;11:Suppl 2: S33-S39.

23. Cummings JL, Mega M, Gray K, Rosenberg-Thompson S, Carusi DA, Gornbein J. The Neuropsychiatric Inventory: comprehensive assessment of psychopathology in dementia. Neurology 1994;44:2308-14.

24. Folstein MF, Folstein SE, McHugh PR. "Mini-Mental State": a practical method for grading the cognitive state of patients for the clinician. J Psychiatr Res 1975;12:189-98. 25. Simpson PM, Surmon DJ, Wesnes KA, Wilcock GK. The cognitive drug research computerized assessment system for demented patients: a validation study. Int J Geriatr Psychiatry 1991;6:95-102.

26. Delis DC, Kaplan E, Kramer JH. DelisKaplan executive function system. San Antonio, Tex.: Psychological Corporation, 2001.

27. Manos PJ, Wu R. The ten point clock test: a quick screen and grading method for cognitive impairment in medical and surgical patients. Int J Psychiatry Med 1994;24: 229-44.

28. Fahn S, Elton RL, Members of the UPDRS Development Committee. Unified Parkinson's disease rating scale. In: Fahn S, Marsden CD, Calne DB, Goldstein M, eds. Recent developments in Parkinson's disease. Florham Park, N.J.: Macmillan Healthcare Information, 1987:153-64.

29. Clegg A, Bryant J, Nicholson T, et al. Clinical and cost-effectiveness of donepezil, rivastigmine and galantamine for Alzheimer's disease: a rapid and systematic review. Health Technol Assess 2001;5:1-137.

30. Doody RS, Stevens JC, Beck C, et al. Practice parameter: management of dementia (an evidence-based review): report of the Quality Standards Subcommittee of the American Academy of Neurology. Neurology 2001;56:1154-66.

31. Stern RG, Mohs RC, Davidson M, et al. A longitudinal study of Alzheimer's disease: measurement, rate, and predictors of cognitive deterioration. Am J Psychiatry 1994;151: 390-6.

Copyright (c) 2004 Massachusetts Medical Society.

POWERPOINT SLIDES OF JOURNAL FIGURES AND TABLES

At the Journal's Web site, subscribers can automatically create PowerPoint slides of Journal figures and tables. Click on a figure or table in the full-text version of any article at www.nejm.org, and then click on PowerPoint Slide for Teaching. A PowerPoint slide containing the image, with its title and reference citation, can then be downloaded and saved. 